\title{
WITHDRAWN: Obesity and overweight among medical college students in Belagavi, Karnataka
}

\author{
Keshab Parajuli ${ }^{\mathrm{a}}$, M.S. Shivaswamy ${ }^{\mathrm{b}}$, Ashwini Narasannavar ${ }^{\mathrm{c}}$, Maginsh Dahal ${ }^{\mathrm{d}, *}$ \\ ${ }^{a}$ Department of Public Health, Asian College for Advance Studies, Lalitpur, Nepal \\ ${ }^{\mathrm{b}}$ Department of Community Medicine, Jawaharlal Nehru Medical College, Karnataka, India \\ ${ }^{c}$ Department of Public Health, Jawaharlal Nehru Medical College, Karnataka, India \\ ${ }^{\mathrm{d}}$ Key Laboratory of Modern Toxicology, Ministry of Education, Nanjing Medical University, Nanjing, 211166, China
}

The Publisher regrets that this article is an accidental duplication of an article that has already been published in Journal of Health Education Research \& Development https://www.omicsonline.org/ open-access/obesity-and-overweight-among-medical-college-studentsin-belagavi-karnataka-109130.html. The duplicate article has therefore been withdrawn.

The full Elsevier Policy on Article Withdrawal can be found at https://www.elsevier.com/about/our-business/policies/articlewithdrawal

\footnotetext{
* Corresponding author.

E-mail address: maginsh@gmail.com (M. Dahal).
} 